\title{
A.JO'ГE
}

African Journal of Teacher Education

ISSN 1916-7822. A Journal of Spread Corporation

Volume 9 No. 22020 Pages 1-22

\section{Class Experiences with Inquiry Learning Spaces in Go-Lab in African Secondary Schools}

\author{
Fer Coenders ${ }^{1}$, Nuno Gomes ${ }^{2}$, Rola Sayegh ${ }^{3}$, \\ Isaac Kinyanjui ${ }^{4}$, Aurelle Noutahi ${ }^{5}$, Nissi Madu ${ }^{6}$ \\ ${ }^{1}$ University of Twente, The Netherlands \\ ${ }^{2}$ NUCLIO, Portugal \\ ${ }^{3}$ IMC, Germany \\ ${ }^{4}$ e-Limu, Kenya \\ ${ }^{5}$ EtriLabs, Republic of Benin \\ ${ }^{6}$ CcHUB, Nigeria**
}

\begin{abstract}
Inquiry Based Learning (IBL) is a form of active learning, often used in STEM education to promote conceptual learning and to acquire scientific investigation skills. This paper reports on a study in which teachers in Kenya, Nigeria and the Republic of Benin implemented IBL embedded in online and offline Inquiry Learning Spaces (ILS) in their classes using the Go-Lab platform (https://www.golabs.eu). After a brief description of the IBL methodology, of lab work and in particular virtual labs for STEM education, of the process of preparing teachers to use IBL in class, and of the context of this study, we highlight the methodology used, and finally report our results. These show that the introduction and class enactment of a digital inquiry based learning platform such as Go-Lab in Africa (i) is possible, although challenging, (ii) does lead to student learning, (iii) for this to take place teacher training is necessary, (iv) the digital infrastructure is
\end{abstract}

** 2. Núcleo Interactivo de Astronomia, São Domingos de Rana, Portugal, http://nuclio.org;

3. Information Multimedia Communication AG, Saarbruecken, Germany, www.im-c.com

4. ELimu Elearning Company Limited, Nairobi, Kenya, http://e-limu.org

5. Educational Technology and Research International, Cotonou, Benin Republic, http://etrilabs.com

6. Co-Creation Hub, Lagos, Nigeria, http://cchubnigeria.com 
present in the schools though minimal and fragile, and (v) a local partner needs to provide assistance when required.

Key words: inquiry-based learning; STEM education; digital learning environment; Go-Lab.

\section{Introduction}

Science and technology is becoming increasingly important in our society. To learn about science and technology is therefore essential for today's students. At a student personal level, this helps them to participate as informed members in society, and the scientific ways of thinking and skills help them in making personal decisions based on evidence. At societal level it will help to cater for sufficient, well-educated practitioners in these areas (Bybee, 2013). Hence there is a compelling need for appropriate Science, Technology, Engineering, and Mathematics (STEM) education, even at secondary school level (De Meester et al., 2020).

In order to stimulate deep conceptual learning, Inquiry Based Learning (IBL) in which students engage in the scientific process, is often used in STEM education (National Academies of Sciences, 2019, 2020). The introduction of IBL in Africa faces a number of challenges. The lack of laboratories and science equipment in schools, and insufficient trained teachers to use IBL, are two of the main obstacles. One possible way to overcome the first obstacle is to replace (part of) the hands-on labs by virtual ones in a digital environment (Gillet et al., 2019). This paper recounts the outcomes of class implementation of digital labs and simulations in an IBL environment in secondary schools in three African countries: Kenya, Nigeria, and the Republic of Benin. Participants 'reactions, teacher learning, organisational support, class implementation, and student learning will be reported.

\section{Conceptual framework}

\section{Inquiry Based Learning}

A meta-analysis of undergraduate STEM education shows that active learning is by far more effective than traditional lecturing (Freeman et al., 2014). Inquiry Based Learning (IBL) can be seen as a specific form of engaged or active learning (de Jong, 2019). In engaged learning, students perform meaningful activities with the learning content, and go beyond the information that is offered to them. In IBL, students are presented a scientific question and by performing investigations or collecting data, they are going to find an answer to this question. Based on the results of the investigations, students infer what this means for the subject domain (Vorholzer, 
von Aufschnaiter, \& Boone, 2020; Xenofontos, Hovardas, Zacharia, \& de Jong, 2020). In contrast to traditional teaching where students often confirm knowledge, in IBL students construct meaning. IBL is not effective when the entire process is left to the students (de Jong, 2019); students need to be given the appropriate level of control (Lazonder \& Harmsen, 2016). Finding the right balance between student and teacher (system) control is not simple (Bevins \& Price, 2016) and this balance depends heavily on the educational contexts and cultures (National Academies of Sciences, 2018): what are the practices students normally engage in, what competences do students have, and what expertise do teachers have, how is learning assessed. Analysis of PISA data has shown that the more open forms of IBL resulted in a more positive attitude towards science, and an increased interest and enjoyment in science, whereas the more closed teacher-centred forms of IBL led to higher knowledge scores (Cairns \& Areepattamannil, 2019). The authors of the last study call for addressing each of the different domains (conceptual, epistemic, social, and procedural), and to allow for an appropriate level of guidance of students. (see also the work of Kirschner, Sweller, \& Clark, (2006), explaining why minimal guidance does not work). So, to assist students develop interest and enjoyment in science along with acquiring specific content knowledge, the degree of openness is crucial.

\section{Lab work}

There is vast evidence that student learning outcome using non-traditional laboratories (virtual and remote) is at least equal to those using traditional labs (hands-on) (Dalgarno, Bishop, Adlong, \& Bedgood, 2009; Rowe, Koban, Davidoff, \& Thompson, 2018; Rutten, van Joolingen, \& van der Veen, 2012). Dalgarno (2009) and colleagues report on studies exploring the effectiveness of a virtual environment based on a chemistry laboratory as a tool to prepare university chemistry students studying at a distance and it was found that the environment was able to be effective as a tool for familiarizing students with the laboratory. Rutten (2012) and his team reviewed literature from the past decade and indicated that their review provides robust evidence that computer simulations can enhance traditional instruction, especially as far as laboratory activities are concerned, even though, in most of this research the use of computer simulations has been approached without consideration of the possible impact of teacher support. Rowe (2018) and colleagues evaluated student experiences in online laboratory courses. Students were surveyed about their satisfaction and perceptions of usability and learning in both hands-on (at home) and computer-based simulation (virtual) labs in a variety of natural science courses. The majority of 
survey respondents felt their online laboratory experience was the same as or better than their prior experiences in the traditional setting. Brinson (2015) carried out a comprehensive review of empirical studies comparing learning outcome achievement using traditional hands-on labs and non-traditional virtual and remote labs, and found that student achievement across all outcome categories (Brinson distinguished: knowledge and understanding, inquiry skills, practical skills, perception, analytical skills, and social and scientific communication) is equal to or higher in nontraditional labs.

Virtual labs have several advantages over hands-on labs: they are cheaper as no labs nor equipment is required, have less environmental impact (no waste), and students have unlimited access and can easily repeat experiments. Preparation before, and cleaning and clearing after a lab, are also different when using virtual labs. Hands-on labs are necessary to master manual skills, like using glassware, pipettes, materials, and equipment.

Especially in times of curriculum renewals, the discussion about the need of lab work and its effectiveness in terms of student learning flares up. This also happened after the introduction of the K-12 Science Framework (Council, 2012) in the USA. The discussion seems to revolve around terminology and epistemic agency (Furtak \& Penuel, 2019; Larkin, 2019; Miller, Manz, Russ, Stroupe, \& Berland, 2018; Osborne, 2019). Furtak and Penuel (2019) argue that students "should engage in scientific inquiry, but with the priority of embedding those experiences in iterative cycles that will lead to the explanation of phenomena ". Osborne (2019) emphasises the "minds on" aspect, and stresses that argue and critique activities are indispensable for scientists and engineers. In this discussion the tension is to mediate between students' experiences and the knowledge of the disciplines we want them to learn. Larkin (2019) contends that public understanding of science education is important and that any communication about this will fail if affective factors, "which are highly activated when discussing science and science education publicly", are not considered.

\section{Virtual labs and Go-Lab}

Combining virtual and remote labs with IBL has resulted in the Go-Lab platform. In this platform (www.golabz.eu), digital labs from different sources, such as the PhET labs, Amrita, Molecular Workbench, ChemCollective, have been brought together. However, this platform is not just a repository of labs, but it also houses a collection of apps and so-called Inquiry Learning Spaces (ILSs). An app is a small software tool that can help students in their inquiry process, such as the 
'Hypothesis Scratchpad' to assist students to formulate a hypothesis, the 'Table Tool' to assist in organizing experimental data, or the "Input box" as a simple note taking tool (https://www.golabz.eu/apps). An Inquiry Learning Space (ILS) is a personalized learning environment for students, consisting of a virtual (or remote) lab, several apps to scaffold student learning, and multimedia material to connect the learning to a context, such as videos, images, external links, and articles. An ILS follows an inquiry cycle. The default inquiry cycle comprises of the phases orientation, conceptualization, investigation, conclusion, and discussion (Pedaste et al., 2015). These are also used in Nigeria and in the Republic of Benin. The Ministry of Education in Kenya decided to use the 5E phases, that is: engage, explore, explain, elaborate, evaluate. Teachers can configure the inquiry cycle they want to use to their own needs in Go-Lab.

ILSs are developed by local teachers, and this is vital as they know their students' needs and interests and understand the educational context and culture at school. Teachers therefore also understand what the appropriate level of student guidance in an ILS should be. And the teachers understand at what level the questions and assignment in the ILS have to be formulated (Tawfik, Graesser, Gatewood, \& Gishbaugher, 2020). When developing an ILS, teachers can start from scratch, or they can copy an existing ILS from another teacher from the Go-Lab website and modify this before using it with their students. The quality of labs, apps and ILSs has been given specific attention at the Go-Lab website: a "rate and comment" function with a five-point scale is available for this.

The use of digital labs on the Go-Lab platform can also be seen in terms of using lab work which is quite common in the natural sciences (Ton de Jong, Linn, \& Zacharia, 2013). The effectiveness of 'normal' lab work however needs to be improved (Millar \& Abrahams, 2009), especially with respect to the use of sufficient "minds on" activities to strengthen cognitive processes. The Go-Lab platform is very well suited to incorporate "minds on" activities in an ILS.

\section{The teachers}

Teachers still play a critical role in the success of their students (National Academies of Sciences, 2019, 2020). Introducing Go-Lab in STEM education will affect the role students and teachers play in class. Teachers no longer transmit knowledge but engage students actively in learning science and mathematics. This requires teacher preparation before (van Uum, Peeters, \& Verhoeff, 2019), and support during class implementation. In order to be successful, teachers need to acquire specific pedagogical content knowledge (PCK) (Shulman, 1986). PCK can be seen as 
an amalgam of content knowledge, pedagogical knowledge, knowledge of the curriculum, knowledge of the students, and knowledge of assessment practices (Gess-Newsome, 1999, 2015; Magnusson, Krajcik, \& Borko, 1999). In order to describe the way teachers integrate ICT skills into their teaching, Technological Pedagogical Content Knowledge (TPCK) has been introduced (Koehler \& Mishra, 2013). A study conducted by Mtebe \& Raphael (2018) in Tanzania showed that teachers confidence level in TPCK is lower than that in Content Knowledge and Pedagogical Knowledge. A study in 30 secondary schools in Kenya revealed that teachers do not feel well prepared for ICT integration at school (Mwangi \& Khatete, 2017). A similar study among mathematics teachers in Kenya confirmed this, and the author recommends intensive training during pre-service and in-service (Amuko, 2015). The teachers involved in GO-GA need to acquire PCK about Inquiry Based Learning (IBL), how this relates to doing lab work and practical activities, and the pedagogies that can be used to effectively teach in the IBL spirit. And on top of this PCK, teachers also need to become familiar with the Go-Lab digital ecosystem (Ton de Jong, Sotiriou, \& Gillet, 2014) in order to develop the ILSs they are going to use with their students (the TPCK). To make the situation even more complex, successful class implementation further requires a proper digital infrastructure at school, which means having sufficient computers or laptops for class use and having stable and fast internet connectivity when using the ILSs online. So, it is not surprising that even after intensive teacher preparation, there might be some hesitation from the side of the teachers to bring their newly developed knowledge and skills into the actual classroom practice (Fullan, 2007).

As teachers in class use routine actions, changing these is complex (Schön, 1983) and teachers will first need to unlearn their previous "repertoire". Preparing teachers is therefore seen as a process, not just an event, it takes time (Fullan, 2007). Different models have been developed to visualize such complex teacher learning (Clarke \& Hollingsworth, 2002; Coenders \& Terlouw, 2015), and these models also apply to learning how to deal with inquiry based learning in a digital environment.

\section{The context of this study}

This paper reports the findings of a study in which teachers implemented an inquiry learning space (ILS) using the Go-Lab platform in their classes. The study was part of GO-GA, a project funded by the European Union (https://go-ga.org), and was conducted in Kenya, Nigeria and the Republic of Benin. The GO-GA consortium consisted of five partners in five European countries, and three 
partners in Africa, one in each of the target countries. In a first study that is not the scope of this paper, only teachers who had internet at school where invited to join. In this study, teachers in schools without internet were encouraged to participate. To facilitate this, an offline viewer had to be developed, this was done by the consortium. This offline viewer will enable students to use a computer to go through the Inquiry Learning Space (ILS) in class without having an internet connection. As a first step, teachers developed the ILS for their students online. They subsequently downloaded this ILS into the offline viewer. Back at school, teachers installed the offline viewer and the ILS on each computer or laptop their students were going to use. And students could now work on the ILS without an internet connection.

Before ILS class implementation, the teachers received training: first an introductory course in IBL, and then an intensive three-day seminar with two main components: (a) how to develop an ILS using the Go-Lab ecosystem, and (b) how to implement an ILS in class. Most teachers implemented the personally developed ILS in class at their school. Some however used an ILS developed by a colleague. During class implementation teachers were supported through a Teacher Implementation Manual, available on paper and as a pdf, an online helpdesk, and email. Additionally, teachers could communicate with each other and the support staff through a WhatsApp group.

This study investigated what happened when teachers implemented an (offline) ILS in class. Because teacher training was an essential feature of this innovation, the following five levels to evaluate teacher professional development were used (Guskey, 2000): 1) participants' reactions; 2) teacher learning; 3) organisation support \& change; 4) participants' use of new knowledge and skills: class implementation; 5) student learning outcomes.

\section{Method}

\section{Participants}

All teachers participated voluntarily. In Kenya, 26 teachers participated, in Nigeria 33, and in Benin 13. These teachers taught 83 ILs classes to over 2400 students.

\section{Instruments}

As schools without internet participated, it was not possible to use online evaluation instruments to evaluate the outcome of this study. Instead paper and pencil questionnaires to gather data from teachers and students were used. These questionnaires were administered at the end of an ILS 
class. In addition, a class implementation report was compiled, and brief teacher- and student interviews immediately after class were conducted.

To get an idea of the magnitude of change for teachers and students, questions about 'normal' class practices were included in the student questionnaire. As a result, the questionnaires contained five categories of questions: class use, teacher satisfaction and preparedness, student satisfaction and learning, pedagogical issues, and 'normal' class practices. For each of these categories, questions were formulated.

The teacher questionnaire contained 16 questions; all were multiple choice or factual questions (for example "How many male students were in class?"). For two multiple choice questions teachers were requested to explain their answer (for example "Please indicate what you are not satisfied with"). The student questionnaire consisted of 14 questions. Four of these were about 'normal class practices'. All questions except one were multiple choice. In this open question, students were requested to indicate what they had learned in their ILS lesson. The class observation report items were factual (for example: "did the lesson start on time and could the students finish on time"). For the teacher and the student interviews a concise interview guide was prepared. The interviews were recorded. All materials were translated into French to accommodate the teachers and students in Benin.

\section{Procedure}

On the day of a class implementation, a local GO-GA staff member visited the school. There were two main reasons for this: a) to assist the teacher with the last preparation of the computers or laptops, and b) to do the evaluation, that is to administer the paper and pencil questionnaires, to conduct the interviews at the end of the lesson, and to compile the class implementation report. The answers to the paper and pencil teacher questionnaires where digitized. A randomly chosen number of the student questionnaires, filled in by student groups in Kenya and by individual students in Nigeria and Benin, was digitized per class. When possible, randomly selected individual students were interviewed whenever possible, while the rest were filling in questionnaires, this to avoid interrupting classes. When possible, the teacher was also interviewed. For each implemented ILS class, a teacher evaluation questionnaire was received: for Kenya 27, for Nigeria 40, and for Benin 16. The numbers of student evaluation questionnaires received were: for Kenya 103 (filled in by student groups), for Nigeria 473, and for Benin 209. Not all teachers 
could be interviewed: in total 10 teacher interviews from Kenya, 14 from Nigeria, and 11 from Benin were received and analyzed, 35 in total. Interviewing students proved challenging, mainly because insufficient time after class to conduct the interviews as students had to rush for a next class. The following numbers of student interviews were received: ten from Kenya, two from Nigeria, and six from Benin, 18 in total. As the number of interviewed teachers and students was limited, these data were used to triangulate the data from questionnaires and the class observation reports.

\section{Data analyses}

The following were data that could be used: 83 teacher evaluation questionnaires, 785 student evaluation questionnaires, 59 class observation reports, 35 teacher interviews and 18 student interviews. For data analysis, the following strategy was used: first, all teacher and student evaluation questionnaires were digitized to an excel form. Subsequently, these data were analysed using descriptive statistics. The answers to the open student question, about what they had learned, were categorised using Grounded Theory Principles (Gibbs, 2018). This resulted in several categories such as: specific content, easier to understand, more fun/enjoyable interesting, computer use, research skills.

For the purposes of validation, similar questions from the teacher- and the student questionnaire were compared. For the same reasons, similar questions from the questionnaire were compared to the class observation report. With respect to the interviews: the first step was to transcribe the audio or video recordings. The data were then summarized using descriptive statistics.

\section{Results and conclusions}

First a few general data. In Kenya, 26 teachers taught 27 ILS classes using 22 different ILSs to 938 students, 455 male and 483 female, in 19 schools. In Nigeria, 724 students, 293 male and 431 female, in 17 schools were taught 40 ILS classes by 33 teachers using 8 different ILSs. In the Republic of Benin: 13 teachers taught 16 ILS classes using 10 different ILSs to 754 students, 418 male and 336 female, in 9 schools. In summary, in all three countries, 83 ILS classes were taught by 72 teachers to 2416 students in 45 schools, using 40 different ILSs. As expected, most of the teachers used an offline ILS (Kenya 85\%; Nigeria 89\%; Benin 100\%).

The data show that class practice in this ILS lesson was not so different from a 'normal' class: 
Doing assignments was rather common: $97 \%$ of the Kenyan students did assignments in class at least regularly, and all students at least regularly at home. In Nigeria, $84 \%$ at least regularly in class and $94 \%$ at least regularly as homework. For Benin, the numbers are: $87 \%$ in class and $95 \%$ at home.

Practical lab work was quite common: in Kenya 97\%, in Nigeria 59\%, and in Benin $72 \%$ of the students do this at least so now and then. This means that setting up and performing an experiment is not new to students.

However, although doing assignments and practical work were activities students had regularly performed in a 'normal' class, the ILS class was different because it was an inquiry-based lesson on the computer:

Computer-based learning was new for large numbers of students (Kenya 42\%; Nigeria 66\%; Benin 67\%).

The rest of the results will be reported using the five levels indicated above: participants' reactions; teacher learning; organisation support and change; participants' use of new knowledge and skills: class implementation; student learning outcomes.

\section{Participants' reactions}

How satisfied were the teachers and the students about this ILS lesson?

Most teachers were satisfied with the lesson, Kenya (88\%), Nigeria (82\%) and Benin (62\%). Some teachers were also interviewed about this, 34 in total, and $90 \%$ of these teachers were very positive. Teachers in Benin experienced quite a few technical problems, for example, due to the use of outdated operating systems causing the computers to crash. Almost all students responded to have liked the ILS lesson, and this was confirmed by their teachers who also thought that their students liked the lesson. Even in Benin more than $90 \%$ of the students indicated to have liked the lesson. The conclusion is that both the teachers as well as the students appreciated the ILS lesson. This is an important first indicator for a successful class implementation.

\section{Teacher learning}

Teacher training and preparation should lead to teacher learning. In this study we asked the teachers after they had taught the ILS in class how well prepared they felt, whether they understand Inquiry Based Learning, and what ILS they had used; whether one they had developed themselves or one from a colleague. Here are the results:

How well prepared to teach did the teachers feel?

All Kenyan teachers felt well prepared to teach the lesson. In Nigeria, $80 \%$ felt well prepared and the rest felt somewhat prepared. In Benin $77 \%$ of the teachers felt well prepared, $15 \%$ a bit, and 
one teacher $(8 \%)$ did not feel prepared at all; this last teacher had not attended the teacher preparation program but was invited by a colleague at school to teach the lesson.

Almost all teachers indicated that they understood the principles of Inquiry Based Learning themselves. Although self-reported by teachers, this result is encouraging as it means that teachers felt comfortable to assist their students in a way that suits IBL.

\section{ILS development.}

Teachers could develop the ILS they wanted to use themselves, they could use one from a colleague, or they could use one from the Go-Lab repository. This last option was not used by these teachers. We noticed that in Kenya, the ILSs were mainly developed by the teachers themselves (88\%); in Nigeria by $30 \%$; and in Benin by $50 \%$. This shows that many teachers used an ILS developed by a colleague teacher, especially in Nigeria and Benin. The reason seems to be that most teachers were based in a so-called STEM Cell school, in which all teachers of STEM subject regularly meet to discuss educational issues (see also "organization support \& change" below).

\section{Level of teacher proficiency in developing student learning materials}

As these teachers during their initial pre-service teacher training were educated to become teachers and not specifically to become developers of student learning material, a substantive part of the teacher training in this study was devoted to assisting them to develop an ILS. One of the important aspects in an ILS is the clarity of the instructions for students. Do the students understand the instructions (know what to do) and are they able to do this?

On this, we noticed that in Kenya, $61 \%$ of the students responded that the instructions were very clear; in Nigeria, 63\%; and for Benin 50\%, with a difference between small (49\%) and larger (66\%) student groups in Benin! Larger student groups rated the clarity of the instructions in the ILS higher. This apparently contradictory result might be related to the fact that their ILS session was more teacher-led and there was more discussion.

After having used the ILS in class most of the 34 interviewed teachers were able to give suggestions for improvements:

In Kenya, these improvements were mainly related to the developed ILS, like a different introduction for the students or more questions to make them think about phenomena. These suggestions were within the power of the teachers themselves; they can make these changes. In Nigeria, the suggestions varied from having more apps and labs available for an ILS, to having 
more symbols for mathematical operations. These suggestions were related to the Go-Lab infrastructure and not to their own developed ILS. However, for Benin the improvements were mainly related to the digital infrastructure. The schools had computers running on old operating systems, and the number of devices in class was also limited.

In conclusion:

- It is important that the teachers develop the ILS themselves since they understand their students, are familiar with the (educational) culture, know the curriculum that has to be taught, and know-how and with what type of tests or exams the students will be assessed.

- According to both the students and the teachers, there is room for improvement of the ILSs. For example, the clarity of the instructions can be improved. As developing student learning material was new to most teachers, they will need a few cycles of development, implementation, and reflection te become better developers.

- Is seems important to tailor the training program even more to the teachers' needs and competences, as one of the observations was that teachers differ greatly in computer literacy. Additionally, when it comes to the development of student learning material, teachers differ strongly, with some having no experience with this at all. A few teachers had already started to use IBL with their students, however, for most this was totally new. Moreover, with respect to the use of practical work, and the use of student cooperative learning, teachers had very diverse experiences and competences.

\section{Organisation support and change}

Support from the school administration and from colleagues is seen as a condition to use an innovative approach in class.

We noticed that support at school level was present as almost all headteachers supported ILS class implementation.

- Teachers in so-called STEM schools, schools where teachers of the STEM subjects regularly meet to discuss educational issues related to their subject, are used to collaboration within their schools. In Nigeria, most participating schools were STEM schools, and this is reflected in the data: 40 ILS classes were taught by 33 teachers at 17 schools, only using 8 different ILSs. This means that they shared the teaching resources, in this case the ILS. In Benin, where 
STEM Cells at schools were also introduced, we noticed a similar trend (see also Teacher Learning above).

- To assist teachers before, during, and after implementation, four sources were available: a Teacher Implementation Manual (TIM) was distributed and used during teacher training, a WhatsApp group within each country was set up, teachers could us the online Go-Lab helpdesk (chat), and teachers could request for assistance through e-mail. The TIM was used during the training and served as a reference manual when teachers were back at their school. Through the WhatsApp group teachers could solicit for advice, even when back at school, from their colleagues.

- Most teachers used the Teacher Implementation Manual (Kenya 23 out of 26 teachers; Nigeria 20 of the 33; Benin 12 of the 13).

- WhatsApp group support came second (in Kenya 8 teachers indicated to have used it; in Nigeria 3; and in Benin 8).

- The online helpdesk and the e-mail option where used very little, only 8 times in total by all teachers. This is not surprising as most schools did not have internet, and communication through chat or e-mail using a phone is not easy.

\section{In conclusion:}

School support, from the headteacher and colleagues, are prerequisites for implementing and sustaining an innovation. More STEM teachers participating in one school stimulates implementation. Additionally, when students can use ILSs in more STEM subject classes, they become more familiar with Inquiry Based Learning, and will gradually develop the competences for this approach. Also, Support, in the form of a Teacher Implementation Manual and a WhatsApp group, during teacher training and when teachers are back at school, is essential.

\section{Teachers' use of new knowledge and skills: class use}

The training program the teachers followed before class implementation focussed on understanding IBL, the development of an ILS, and what to do in class (teachers and students). The training was therefore geared towards ultimate class use. The main observations during class use were that the number of devices per group varied strongly.

- Up to 4 students in a group is considered workable, when a group has more students than 4 it is impossible for each of the students to fully participate in the work. In this study we noticed 
that, for Kenya, just more than half of the groups consisted of up to four students; for Nigeria this was 63\%; and for Benin it was only 33\%. This means that the group size in most countries was rather high, too high for effective learning. It is necessary to explore alternatives, such as having only half of the students work on the ILS in class and let the others take on other activities, and then swap in the next period. Or use one computer plus a projector, and go through the ILS with the whole class, a teacher-led ILS class. The teacher can ask small student groups to discuss each specific task in the ILS, and then assist students to formulate a response as a class.

- Class size varied widely. In Kenya, the average class size was 35 students, in Nigeria 18, and in Benin 47. When we take the number of 4 students per group as a starting point (see above), this means that in Benin at least 12 per class devices are required!

- The use of a digital platform for teaching and learning where the students are in control, also means that the teachers must take up a different role. In class, the teachers

○ monitored groups (Kenya 20 teachers (out of 26); Nigeria 26 (out of 33); Benin 12 (out of $13)$,

○ answered questions (Kenya 13 teachers; Nigeria 22; Benin 10),

○ explained content to the class (Kenya 11 teachers; Nigeria 25; Benin 3),

○ explained the procedure to the class (Kenya 8 teachers; Nigeria 24; Benin 8).

- Ideally explaining content or the procedure to the whole class should not be necessary (or only occasionally) as the ILS should connect to students' prior knowledge, and the instructions in the ILS should explain the procedure clearly.

- What kind of assistance did the teachers have to provide, with the content, with computer use or with the inquiry process. Our data reveal that teacher assistance was provided in the following way:

- In Kenya $70 \%$ of the students responded to have needed help; even $85 \%$ of the teachers indicated this: $31 \%$ required help with content, $35 \%$ computer use and $19 \%$ for IBL.

- In Nigeria $57 \%$ of the students indicated to have needed help from their teacher; even $85 \%$ of the teachers said to have helped the students: $55 \%$ related to the inquiry process, $25 \%$ related to content and $5 \%$ to computer use.

$\circ$ In Benin $75 \%$ of the students indicated to have needed help; according to the teachers even 95\%: $50 \%$ for computer use, $38 \%$ the inquiry process and $6 \%$ for content. 
We noticed clear differences between the three countries. In Benin most of teacher help was for computer use, this might also be related to the issue of computers with outdated operating systems.

- Quite a few teachers in Kenya (52\%), Nigeria (37\%) and Benin (56\%) experienced problems in class; like not working ILSs offline (because of technical problems), or because parts of ILSs were not working properly offline. We do not know whether these problems emerged because of technical issues related to Go-Lab, to the use of computers running on old operating systems, or to improper use of apps and labs.

- Technical problems were reported by students in Kenya (29\%), Nigeria (31\%), and Benin (56\%), such as misfunctioning of the technique, due mainly to crashed or very slow computers.

In conclusion:

Teachers were able to successfully use an ILSs in class. The Teacher Implementation Manual and the WhatsApp groups were used to find, or to solicit for, support. They were able to connect seamlessly with students' prior and prerequisite knowledge in the ILS, both with respect to content as for computer use, will make student learning less dependent on teacher assistance, and boost students' sense of agency.

As IBL was new to students, the level of student support in the ILS needs to be higher. When students gain more experience with IBL, this scaffolding in the ILSs can gradually be reduced. Better alignment of the teacher training with the local context, such as the number of available devices and the computer literacy of teachers and students, will also strengthen class implementation. An example of this is paying explicit attention during the teacher training to those pedagogies that most likely will be used in the classrooms (like the example above, to effectively use one computer plus a projector in class).

\section{Student learning outcomes}

An innovative approach must yield at least as much knowledge and skills in students as the pedagogies used before. One of the indicators for student learning is whether they were able to finish the work, and whether they were able to write down what they had learned. We noticed that:

- With respect to finishing the ILS, most students in Kenya finished the ILS (95\%). In Nigeria this was $85 \%$; and in Benin this was lower, $80 \%$. This might be caused by classes starting late 
due to technical problems with the computers as was reported above and due to computer crashes.

- Students mentioned to have learned specific content (Kenya 40\%; Nigeria 61\%; Benin 42\%). Examples of what students mentioned are, "Atomic structure, what are isotopes and examples of isotopes"; "Ohm's law"; "I have learned to construct a graph of tangent, cosine and sine”; "I learned how plants grow with the help of photosynthesis".

- Students mentioned that it was easier or more fun (Kenya, 50\%; Nigeria 10\%; Benin 39\%). Examples of answers are, "I learnt that using computers to learn actually made it easier to learn"; "I Learnt that using computers in learning is a very fun aspect of learning and also helps in expanding our knowledge on the topic"; and "The simple and more interesting way of learning chemistry".

Although we did not actually assess students' knowledge gains through a summative test, the fact that the students were able to indicate what they had learned, and the fact that a large number of students mentioned content gains, can be seen as an indication of student learning.

So, the conclusion is that class use did lead to student learning. However, this can certainly be enhanced through improvements in the ILS.

\section{Discussion}

\section{The infrastructure}

The use of Inquiry Based Learning in a digital infrastructure (Go-Lab) presupposes a few things. First, the users, both teachers and students, need to have a basic understanding of computers. Second, schools need to have sufficient computers available with up-to-date operating systems and anti-virus programs. When these presuppositions are met, ILS class implementation would be more effective.

Teachers were not trained to develop learning material for their students. Therefore, developing an ILS needs to be made as simple as possible so that the teachers can focus on the content instead of the infrastructure. It is imperative that local teachers need to develop the ILS themselves (National Academies of Sciences, 2020). What can be left to students in an ILS and what needs to be given or supported is not a simple matter, as this also heavily depends on what students are used to. This means that the context determines the amount of scaffolding in an ILS. It is however important that students are given the appropriate level of control in an ILS (Bevins \& Prince, 2016; de Jong, 2019; Lazonder \& Harmsen, 2026). 


\section{Teacher participation and commitment}

For the participating teachers this study entailed two innovations at the same time, the introduction of a student-centered IBL pedagogy (Vorholzer et al., 2020; Xenofontos et al., 2020) in which the student groups determine the pace, the order of going through an ILS, and the way they want to collaborate in their group, as well as the use of a digital environment (Ton de Jong et al., 2014) in a complex school context.

We noticed that for quite a few teachers, class implementation was especially challenging. There are different reasons for this but the main uncertainty for teachers was how the students were going to react. The teachers' confidence level is important (Amuko, 2015; Mtebe \& Raphael, 2018; Mwangi \& Khatete, 2017). Also important in this are students' computer competency levels, how they perceive inquiry-based learning, and how they collaborate. And of course, whether the students will be able to understand the tasks in the ILS.

Class introduction of an ILS poses challenges for the teachers themselves as well. When lecturing and explaining content, they have the control of the class, but when students are given the control, what do the teachers have to do? What are their new roles in class, and how can they execute these roles? How can they be trained for these new roles? So, preparing teachers for this is not simple, it is certainly not an event but a complex process (Author, 2015; Fullan, 2007). It will take time.

\section{Local partner}

It was necessary to have a member from the local partner present at school on the day of the ILS class. This member assisted in setting it all up and served to encourage the teachers to scale the hurdles that came up. Without the presence and support from these local partners, teachers would probably have cancelled or postponed many ILS classes.

Finally, this study showed that the introduction and class enactment of a digital Inquiry Based Learning platform in each of the three African countries is possible and does lead to student learning. For this to take place it is important to train the teachers, to make sure the digital infrastructure at school is present, and it helps a lot when a local partner can provide assistance when needed.

\section{Acknowledgment}

This work was funded by the European Union's Horizon 2020 research and innovation program under the Grant Agreement no 781012. We are greatly indebted to the teachers in Kenya, Nigeria 
and the Republic of Benin who took part in this adventure. They participated voluntarily, without external incentives. Their sole reason to participate was to improve their students' education.

\section{References}

Amuko, S. (2015). Pedagogocal Practices in Integration of ICT in Teaching and Learning Mathematics, in Secondary schools in Nairobi County, Kenya. Journal of Mathematics, 11(5), 20-23.

Bevins, S., \& Price, G. (2016). Reconceptualising inquiry in science education. International Journal of Science Education, 38(1), 17-29. Retrieved from http://dx.doi.org/10.1080/09500693.2015.1124300. doi:10.1080/09500693.2015.1124300

Brinson, J. R. (2015). Learning outcome achievement in non-traditional (virtual and remote) versus traditional (hands-on) laboratories: A review of the empirical research. Computers \& Education, 87, 218-237. Retrieved from http://www.sciencedirect.com/science/article/pii/S0360131515300087. doi:https://doi.org/10.1016/j.compedu.2015.07.003

Bybee, R., W. . (2013). The Case for STEM Education: Challenges and Opportunities. Arlington, Viginia: National Science Teachers Association Press.

Cairns, D., \& Areepattamannil, S. (2019). Exploring the Relations of Inquiry-Based Teaching to Science Achievement and Dispositions in 54 Countries. Research in Science Education, 49(1), 1-23. Retrieved from https://doi.org/10.1007/s11165-017-9639-x. doi:10.1007/s11165-017-9639-x

Clarke, D., \& Hollingsworth, H. (2002). Elaborating a model of teacher professional growth. Teaching and Teacher Education, 18(8), 947-967. Retrieved from http://www.sciencedirect.com/science/article/B6VD8-473TYWF4/2/d7e0e88034b935522c9e8a6bf1de3a2f

Coenders, F., \& Terlouw, C. (2015). A Model for In-service Teacher Learning in the Context of an Innovation. Journal of Science Teacher Education, 26(5), 451-470. Retrieved from http://dx.doi.org/10.1007/s10972-015-9432-5. doi:10.1007/s10972-015-9432-5

Council, N. R. (2012). A Framework for K-12 Science Education: Practices, Crosscutting Concepts, and Core Ideas. Washington, DC: The National Academies Press.

Dalgarno, B., Bishop, A. G., Adlong, W., \& Bedgood, D. R. (2009). Effectiveness of a Virtual Laboratory as a preparatory resource for Distance Education chemistry students. Computers \& Education, 53(3), 853-865. Retrieved from 
http://www.sciencedirect.com/science/article/pii/S036013150900116X. doi:https://doi.org/10.1016/j.compedu.2009.05.005

de Jong, T. (2019). Moving towards engaged learning in STEM domains; there is no simple answer, but clearly a road ahead. Journal of Computer Assisted Learning, 35(2), 153-167. Retrieved from <Go to ISI>://WOS:000461057100001. doi:10.1111/jcal.12337

de Jong, T., Linn, M. C., \& Zacharia, Z. C. (2013). Physical and Virtual Laboratories in Science and Engineering Education. Science, 340(6130), 305-308. Retrieved from https://science.sciencemag.org/content/sci/340/6130/305.full.pdf. doi:10.1126/science.1230579

de Jong, T., Sotiriou, S., \& Gillet, D. (2014). Innovations in STEM education: the Go-Lab federation of online labs. Smart Learning Environments, 1(1), 3. Retrieved from https://doi.org/10.1186/s40561-014-0003-6. doi:10.1186/s40561-014-0003-6

De Meester, J., Boeve-de Pauw, J., Buyse, M.-P., Ceuppens, S., De Cock, M., De Loof, H., . . . Dehaene, W. (2020). Bridging the Gap between Secondary and Higher STEM Education - the Case of STEM@ school. European Review, 28(S1), S135-S157. Retrieved from https://www.cambridge.org/core/article/bridging-the-gap-between-secondary-and-higher-stemeducation-the-case-of-stemschool/A72252C65FA0A74921DF3EB5844AC269. doi:10.1017/S1062798720000964

Freeman, S., Eddy, S. L., McDonough, M., Smith, M. K., Okoroafor, N., Jordt, H., \& Wenderoth, M. P. (2014). Active learning increases student performance in science, engineering, and mathematics. Proceedings of the National Academy of Sciences, 111(23), 8410-8415. Retrieved from https://www.pnas.org/content/pnas/111/23/8410.full.pdf. doi:10.1073/pnas.1319030111

Fullan, M. G. (2007). The new meaning of educational change. (4th ed. ed.). New York: Teachers College Press.

Furtak, E. M., \& Penuel, W. R. (2019). Coming to terms: Addressing the persistence of "hands-on" and other reform terminology in the era of science as practice. Science Education, 103(1), 167-186. Retrieved from https://onlinelibrary.wiley.com/doi/abs/10.1002/sce.21488. doi:10.1002/sce. 21488

Gess-Newsome, J. (1999). Pedagogical content knowledge: an introduction and orientation. In J. GessNewsome \& N. G. Lederman (Eds.), Examining pedagogical content knowledge (pp. 3-17). Dordrecht: Kluwer Academic Publishers. 
Gess-Newsome, J. (2015). A model of teacher professional knowledge and skill including PCK. In A. Berry, P. Friedrichsen, \& L. John (Eds.), Re-examining Pedagogical Content Knowledge in Science Education (pp. 28-42). London: Routledge.

Gibbs, J. R. (2018). Analyzing qualitative data. London: SAGE Publications Ltd, 2nd edition.

Gillet, D., Tijani, B., Beheton, S., Fara, J. C., Dikke, D., Noutahi, A., . . Gavaud, C. e. (2019). Promoting and Implementing Digital STEM Education at Secondary Schools in Africa. Paper presented at the 2019 IEEE Global Engineering Education Conference (EDUCON), Dubai, United Arab Emirates.

Guskey, T. R. (2000). Evaluating professional development. California: Corwin Press.

Kirschner, P. A., Sweller, J., \& Clark, R. E. (2006). Why Minimal Guidance During Instruction Does Not Work: An Analysis of the Failure of Constructivist, Discovery, Problem-Based, Experiential, and Inquiry-Based Teaching. Educational Psychologist, 41(2), 75-86. Retrieved from https://doi.org/10.1207/s15326985ep4102_1. doi:10.1207/s15326985ep4102_1

Koehler, M. J., \& Mishra, P. (2013). What is Technological Pedagogical Content Knowledge (TPACK)? Contemporary Issues in Technology and Teacher Education, 9(1), 60-70.

Larkin, D. B. (2019). Attending to the public understanding of science education: A response to Furtak and Penuel Science Education, 103(5), 1294-1300. Retrieved from https://onlinelibrary.wiley.com/doi/abs/10.1002/sce.21537. doi:10.1002/sce.21537

Lazonder, A. W., \& Harmsen, R. (2016). Meta-Analysis of Inquiry-Based Learning: Effects of Guidance. Review of Educational Research, 86(3), 681-718. Retrieved from https://journals.sagepub.com/doi/abs/10.3102/0034654315627366. doi:10.3102/0034654315627366

Magnusson, S., Krajcik, J., \& Borko, H. (1999). Nature, sources, and development of pedagogical content knowledge for science teaching. In J. Gess-Newsome \& N. G. Lederman (Eds.), Examining Pedagogical Content Knowledge (pp. 95-132). Dordrecht: Kluwer Academic Publishers.

Millar, R., \& Abrahams, I. (2009). Practical work: making it more effective. School Science Review, 91(334), 59-64.

Miller, E., Manz, E., Russ, R., Stroupe, D., \& Berland, L. (2018). Addressing the epistemic elephant in the room: Epistemic agency and the next generation science standards. Journal of Research in 
Science Teaching, 55(7), 1053-1075. Retrieved from

https://onlinelibrary.wiley.com/doi/abs/10.1002/tea.21459. doi:10.1002/tea.21459

Mtebe, J. S., \& Raphael, C. (2018). Eliciting In-service Teachers’ Technological Pedagogical

Content Knowledge for 21st-Century Skills in Tanzania. Journal of Learning for Development, 5(3), 263-279.

Mwangi, M. I., \& Khatete, D. (2017). TEACHER PROFESSIONAL DEVELOPMENT NEEDS FOR PEDAGOGICAL ICT INTEGRATION IN KENYA: LESSONS FOR TRANSFORMATION. European Journal of Education Studies, 634-648. Retrieved from https://oapub.org/edu/index.php/ejes/article/view/787. doi:10.46827/ejes.v0i0.787

National Academies of Sciences, E., and Medicine. (2018). How People Learn II: Learners, Contexts, and Cultures. Washington, DC: The National Academies Press.

National Academies of Sciences, E., and Medicine. (2019). Science and Engineering for Grades 6-12. Investigation and Design at the Center. Washington, DC: The National Academies Press.

National Academies of Sciences, E., and Medicine. (2020). Changing Expectations for the K-12 Teacher Workforce: Policies, Preservice Education, Professional Development, and the Workplace. Washington, DC: The National Academies Press.

Osborne, J. F. (2019). Not "hands on" but "minds on": A response to Furtak and Penuel. Science Education, 103(5), 1280-1283. Retrieved from https://onlinelibrary.wiley.com/doi/abs/10.1002/sce.21543. doi:10.1002/sce.21543

Pedaste, M., Mäeots, M., Siiman, L. A., de Jong, T., van Riesen, S. A. N., Kamp, E. T., . . Tsourlidaki, E. (2015). Phases of inquiry-based learning: Definitions and the inquiry cycle. Educational Research Review, 14, 47-61. Retrieved from http://www.sciencedirect.com/science/article/pii/S1747938X15000068. doi:https://doi.org/10.1016/j.edurev.2015.02.003

Rowe, R. J., Koban, L., Davidoff, A. J., \& Thompson, K. H. (2018). Efficacy of Online Laboratory Science Courses. Journal of Formative Design in Learning, 2(1), 56-67. Retrieved from <Go to ISI>://WOS:000467809400006. doi:10.1007/s41686-017-0014-0

Rutten, N., van Joolingen, W. R., \& van der Veen, J. T. (2012). The learning effects of computer simulations in science education. Computers \& Education, 58(1), 136-153. Retrieved from <Go to ISI>://WOS:000298524300014. doi:10.1016/j.compedu.2011.07.017 
Schön, D. (1983). The Reflective Practitioner: How professionals think in action. London: Temple Smith.

Shulman, L. S. (1986). Those who understand, knowledge growth in teaching. Educational Researcher, $14(2), 4-14$.

Tawfik, A. A., Graesser, A., Gatewood, J., \& Gishbaugher, J. (2020). Role of questions in inquiry-based instruction: towards a design taxonomy for question-asking and implications for design. Educational Technology Research and Development, 68(2), 653-678. Retrieved from https://doi.org/10.1007/s11423-020-09738-9. doi:10.1007/s11423-020-09738-9

van Uum, M. S. J., Peeters, M., \& Verhoeff, R. P. (2019). Professionalising Primary School Teachers in Guiding Inquiry-Based Learning. Research in Science Education. Retrieved from https://doi.org/10.1007/s11165-019-9818-z. doi:10.1007/s11165-019-9818-z

Vorholzer, A., von Aufschnaiter, C., \& Boone, W. J. (2020). Fostering Upper Secondary Students' Ability to Engage in Practices of Scientific Investigation: a Comparative Analysis of an Explicit and an Implicit Instructional Approach. Research in Science Education, 50(1), 333-359. Retrieved from https://doi.org/10.1007/s11165-018-9691-1. doi:10.1007/s11165-018-9691-1

Xenofontos, N. A., Hovardas, T., Zacharia, Z. C., \& de Jong, T. (2020). Inquiry-based learning and retrospective action: Problematizing student work in a computer-supported learning environment. Journal of Computer Assisted Learning, 36(1), 12-28. Retrieved from https://onlinelibrary.wiley.com/doi/abs/10.1111/jcal.12384. doi:10.1111/jcal.12384 